\title{
Octave generalization and the identification of distorted melodies
}

\author{
WILLIAM J. HOUSE \\ University of South Carolina, Aiken, South Carolina 29801
}

\begin{abstract}
Four familiar melodies were distorted in such a way that certain harmonic information was maintained. These melodies and their nondistorted versions were randomly presented to three groups of musically untrained subjects. There were, thus, undistorted melodies which were equal in all ways except the frequencies of the constituent tones, three conditions in which only the octave was maintained, and three other harmonic control conditions in which only the perfect fifth, fourth, and major third were maintained. The melodic sequences were presented to each group using a different tonal waveform for each group: sine wave, rectangular wave, and sawtooth wave. An analysis of variance revealed that the octave distortions were significantly more recognizable than the control conditions. Furthermore, waveform significantly influenced identification of melodies. It was proposed that octave generalization was a major factor in the identification of the distorted octave sequences.
\end{abstract}

A succession of tones which may vary in pitch and duration produces melody (Cooper, 1973). This definition, which includes the motif, tone row, and other musical constructions, describes the basic element of most western music. Thus, when music is seen as a kind of communication or information, melody can be viewed as a fundamental component of the musical language.

The obviously holistic nature of the melodic stimulus has led many workers to approach the problem of the processing of melody information from the point of view that melodies are fundamentally to be treated as gestalts. This position, emphasized, for example, by von Fieandt (1966), has led to studies which involve observing the ability of subjects to identify distortions of the whole pattern of a melody. Dowling (1972), for example, observed that subjects could identify inversions, retrogrades, and retrograde inversions of melodies. It further seems that subjects can identify melodies in which only the contour (i.e., the patterns of ups and downs of the tone) is maintained (Dowling \& Fujitani, 1971). It is thus clear that the human auditory system is sensitive to the general pattern of ups and downs of a melody line and can readily deal with a succession of tones as a whole, irrespective of harmonic relationships among the individual tones. White (1960) further supported this idea by demonstrating that subjects were capable of recognition of many different melodic transformations which involved systematically changing the intervals of well-known melodies.

Révész (1913) suggested that pitch should be con-

The author wishes to thank William Rhoden for technical aid in the preparation of this study. sidered in terms of "tone height" which ascends continuously as frequency increases and "chroma" which is repeated every octave. Consequently, two tones separated by an octave differ in "tone height", but share "chroma." Another sort of melodic transformation often found in music is one in which the "chroma" of a melody is maintained while the "tone height" is manipulated. The identification of such a transformation of a tonal sequence would be traditionally explained in terms of octave generalization, that is, the difficulty that subjects have discriminating frequencies of a ratio of $1: 2$.

Another position, however, has been recently presented: Deutsch (1969) noted the dissimilarity between the ability to identify simultaneous pitches and successions of pitches (melody). These behaviors are so different, she concluded, that there must be two concomitant neuronal systems-one operating in the recognition of pitch and the other in melody recognition. The relational properties of the tonal combinations are consequently seen as being processed in a different manner from the tones themselves.

From the dual-system model, one would predict that if tones of a familiar melody are scrambled with the restriction that octave information is maintained, the melody information will be lost entirely; octave generalization will be of no assistance in recognition.

Deutsch (1972) performed such an experiment. The first half of the tune "Yankee Doodle" was employed under five conditions. Recognition percentages were obtained from groups which listened to the undistorted melody in one of three octaves, the rhythm of the melody alone, and of a random octave distortion. This latter experimental treatment consisted of the melody with the tones randomly selected 
from the three octaves of the undistorted melody control conditions. The control groups listening to the undistorted melody unanimously identified the melody, usually after the first few tones. The random octave treatment was recognized by $12 \%$ of the group, and the rhythm-only treatment was recognized by $19 \%$ of the listeners. Deutsch argued that the recognition of the random octave treatment was below chance and that octave generalization was not aiding in the recognition of the melody. Thus, she concluded that these data were in support of the dual-system theory of melody recognition.

The present investigation was designed to further test the dual-process theory. It is conceivable that there would be a difference in identification of a distorted melody using melodies other than Yankee Doodle, which was used in Deutsch's (1972) study. Consequently, four melodies were used in the present experiment. The melodies were presented with identical rhythms in order to eliminate the problem of recognition on the basis of rhythmic information (see White, 1960). Furthermore, only the first seven tones of the melodies were used since it had been found that subjects could identify melodies from this amount of information (White, 1960).

The octave distortion results in an erratic sequence of tones with rather large jumps between tones. The distortion of contour, rather than the subject's inability to use octave information in identification, may interfere with recognition. In the present study, therefore, the subject listened to the four melodies in an undistorted treatment, an octave distortion like that used by Deutsch, and to distortions using only two octaves in alternation. As a control condition, treatments using the next three intervals of the harmonic series after the octave-the perfect fifth, the fourth, and the major third-were also used. If octave generalization does not aid in the recognition of the octave distortion, then there is no reason to expect that the other harmonic interval permutations would be recognized either.

The final variable that was manipulated in the present study was the harmonic content of the constituent tones of the sequences. Groups of subjects listened to all of the distortions in either sine-wave, sawtooth, or rectangular waveform tones. This variation of harmonic information across groups served the purpose of determining the influence of the harmonic content of tones on recognition of the distortions. The sawtooth waveform includes octaves among the upper harmonics. Higher identification of this condition would implicate recognition in terms of the presence of the appropriate octave information in the stimulus rather than generalization from the octave. In music, harmonics are almost always found in the stimulus. Consequently, the manipulation of harmonics would clarify what occurs in stimuli more like actual music than computer-controlled sine wave tones.

\section{METHOD}

\section{Subjects}

The subjects were 51 undergraduate students at the University of South Carolina-Aiken who had no hearing problems. The experimental sessions involved groups of 16 (sine), 17 (rectangular), and 18 (sawtooth). There were 25 males and 26 females, all of whom had had no significant musical training.

\section{Stimuli}

The first seven tones of four melodies were used. These melodies were selected using two criteria: the melodies were well-known children's songs and the first seven tones of all of the tunes could be played with identical rhythm (i.e., seven temporally equal tones and intertone intervals) with minimal distortion of the tune's usual rhythm. The equality of the rhythm was seen to be important because of the finding by White (1960) that such melodies can be identified with only rhythmic information. The melodies used in the present study were Yankee Doodle, Old McDonald Had a Farm, Are You Sleeping? (Frère Jacque), and Twinkle Twinkle Little Star. Each of the melodies was played in the key of F major; the tones were taken from the equal tempered scale (International pitch, $A=435 \mathrm{~Hz}$ ). For each melody there were three undistorted conditions in three different octaves, $F_{3}=173 \mathrm{~Hz}$, $F_{4}=345 \mathrm{~Hz}$, and $F_{5}=691 \mathrm{~Hz}$ (these are the low frequencies of the octave). Three octave distortion conditions were constructed from the tones of these three octaves. One octave dis tortion condition was made by alternating tones from the central octave to the octave above; another condition consisted similarly of alternating from the central octave to the octave below. A sixth octave condition was like that used by Deutsch (1972). It was accomplished by selecting randomly from the tones of the three octaves of the undistorted conditions. The only time that this random method was not followed was in the case in which two successive tones were chosen which also occurred in the undistorted melody. The fifth, fourth, and third distortion conditions were constructed like the single-octave distortion conditions

Table 1

Tones* Used to Generate Four Melodies in Undistorted, Alternating Octaves, Three Random Octaves, Alternating Fifths, Fourths, and Thirds Treatments

\begin{tabular}{|c|c|c|c|c|}
\hline Treatments & Frere & Twinkle & Yankee & McDonald \\
\hline Undistorted & $\begin{array}{l}\mathrm{F}_{4} \mathrm{G}_{4} \\
\mathrm{~F}_{4} \mathrm{G}_{4}\end{array}$ & $\begin{array}{l}\mathrm{F}_{4} \mathrm{~F}_{4} \\
\mathrm{D}_{5} \mathrm{D}\end{array}$ & $\begin{array}{l}F_{4} F_{4} G_{4} A_{4} \\
F_{4} A_{4} G_{4}\end{array}$ & $\begin{array}{l}\mathrm{F}_{4} \mathrm{~F} \\
\mathrm{D}_{4} \mathrm{D}\end{array}$ \\
\hline $\begin{array}{l}\text { Random } \\
\text { Octave }\end{array}$ & $\begin{array}{l}\mathrm{F}_{3} \mathrm{G}_{4} \mathrm{~A} \\
\mathrm{~F}_{4} \mathrm{G}_{3} \mathrm{~A}\end{array}$ & $\begin{array}{l}\mathrm{F}_{4} \mathrm{~F}_{3} \mathrm{C}_{5} \mathrm{C}_{4} \\
\mathrm{D}_{5} \mathrm{D}_{4} \mathrm{C}_{5}\end{array}$ & $\begin{array}{l}F_{3} F_{5} G_{4} A_{3} \\
F_{5} A_{4} G_{5}\end{array}$ & $\begin{array}{l}\mathrm{F}_{4} \mathrm{~F}_{3} \mathrm{~F}_{4} \mathrm{C}_{5} \\
\mathrm{D}_{4} \mathrm{D}_{5} \mathrm{C}_{6}\end{array}$ \\
\hline $\begin{array}{l}\text { Alternating } \\
\text { Higher } \\
\text { Octave }\end{array}$ & $\begin{array}{l}F_{4} G_{5} A \\
F_{4} G_{5} A\end{array}$ & $\begin{array}{l}\mathrm{F}_{4} \mathrm{~F}_{5} \mathrm{C}_{5} \mathrm{C}_{6} \\
\mathrm{D}_{3} \mathrm{D}_{6} \mathrm{C}_{3}\end{array}$ & $\begin{array}{l}F_{4} F_{5} G_{4} A_{5} \\
F_{4} A_{5} G_{4}\end{array}$ & $\begin{array}{l}\mathrm{F}_{4} \mathrm{~F}_{5} \mathrm{~F}_{4} \mathrm{C}_{5} \\
\mathrm{D}_{4} \mathrm{D}_{5} \mathrm{C}_{4}\end{array}$ \\
\hline $\begin{array}{l}\text { Alternating } \\
\text { Lower } \\
\text { Octave }\end{array}$ & $\begin{array}{l}F_{4} G \\
F_{4} G\end{array}$ & & $\begin{array}{l}F_{4} F_{3} G_{4} A_{3} \\
F_{4} A_{3} G_{4}\end{array}$ & $\begin{array}{l}\mathrm{F}_{4} \mathrm{~F}_{3} \mathrm{~F}_{4} \mathrm{C}_{3} \\
\mathrm{D}_{4} \mathrm{D}_{3} \mathrm{C}_{4}\end{array}$ \\
\hline Fifth & & $\begin{array}{l}\mathrm{F}_{4} \mathrm{C}_{5} \mathrm{C}_{5} \mathrm{G}_{5} \\
\mathrm{D}_{5} \mathrm{~A}_{5} \mathrm{C}_{5}\end{array}$ & $\begin{array}{l}F_{4} C_{5} G_{4} E_{5} \\
F_{4} E_{5} G_{4}\end{array}$ & $\begin{array}{l}\mathrm{F}_{4} \mathrm{C}_{5} \mathrm{~F} \\
\mathrm{D}_{4} \mathrm{~A}_{4}\end{array}$ \\
\hline Fourth & $\begin{array}{l}\mathrm{F}_{4} \mathrm{C}_{5} \mathrm{~A}_{4} \\
\mathrm{~F}_{4} \mathrm{C}_{5} \mathrm{~A}_{4}\end{array}$ & 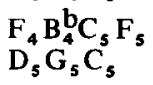 & $\begin{array}{l}\mathrm{F}_{4} \mathrm{~B}_{4}^{\mathrm{b}} \mathrm{G}_{4} \mathrm{D}_{4} \\
\mathrm{~F}_{4} \mathrm{D}_{5} \mathrm{G}_{4}\end{array}$ & 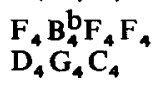 \\
\hline Third & $\begin{array}{l}\mathrm{F}_{4} \mathrm{~B}_{4}^{\mathrm{b}} \mathrm{A}_{4} \mathrm{~A} \\
\mathrm{~F}_{4} \mathrm{~B}_{4}^{\mathrm{b}} \mathrm{A}_{4}\end{array}$ & $\begin{array}{l}\mathrm{F}_{4} \mathrm{~A}_{4} \mathrm{C}_{5} \mathrm{E}_{5} \\
\mathrm{D}_{4} \mathrm{~F}_{5} \mathrm{C}_{5}\end{array}$ & $\begin{array}{l}\mathrm{F}_{3} \mathrm{~A}_{4} \mathrm{G}_{4} \mathrm{C}_{4} \\
\mathrm{~F}_{4} \mathrm{C}_{5} \mathrm{G}_{4}\end{array}$ & $\begin{array}{l}\mathrm{F}_{4} \mathrm{~A}_{4} \mathrm{~F}_{4} \mathrm{E}_{4} \\
\mathrm{D}_{4} \mathrm{~F}_{4} \mathrm{C}_{4}\end{array}$ \\
\hline
\end{tabular}

*After Young (1939) 
above. The tones alternated between the central octave $\left(F_{4}=\right.$ $345 \mathrm{~Hz}$ was the low tone of that octave) and a perfect fifth above, a fourth above, or a major third above that tone. This rule was only violated in these few cases in which a true interval would violate the key center of the melody.

All of the seven tone sequences were generated on an Electrocomp 400 audio synthesizer; the tones were recorded at 72 pulses/ min. The durations of the tones were controlled by an Electrocomp 401 sequencer.

The melody conditions were selected randomly and recorded with two presentations each. The sequences were separated by $5 \mathrm{sec}$ of silence between the two playings and $10 \mathrm{sec}$ between the different melody conditions. The number of the sequences was announced before each pair of melody presentations was performed.

\section{Procedure}

The subjects were given an answer sheet on which they placed their responses to the melodies. They were requested to tell if they had hearing problems and to relate the nature of the problem. Subjects with hearing problems were eliminated from the study. The subjects were also requested to describe their background in music and any musical training they had had.

At the top of the sheet were the titles of the four melodies mixed in with six other well-known tunes: Mary Had a Little Lamb, My Bonny Lies Over the Ocean, Jingle Bells, Home on the Range, America the Beautiful, and Row Row Row Your Boat. The subjects were instructed to listen to each of the 36 sequences, each played twice, and to select one of the 10 tunes which they believed to be the correct choice. This selection was then to be written in on the answer sheet. Guessing was encouraged.

\section{RESULTS}

An analysis of variance of the distorted melodies (excluding the melodies in the undistorted form) revealed a significant distortion condition effect $(\mathrm{F}=9.34, \mathrm{df}=5 / 1181, \mathrm{p}<.0001)$. Tukey paired comparisons demonstrated that most of this variance was found between the three octave treatments and the other harmonic distortions. The three octaves treatments did not significantly differ from each other; nor did the three other harmonic conditions differ from each other.

There was, furthermore, a significant melody effect $(F=6.64$, df $=3 / 1181, p<.0004)$. Tukey analyses showed that the major variance in this effect was in the identification of Yankee Doodle; the other melodies did not produce significantly different identification rates from each other.

A significant main effect for wave condition was also found $(\mathrm{F}=4.23, \mathrm{df}=2 / 1181, \mathrm{p}<.02)$. Tukey tests disclosed that the major source of variance in this effect was for identification of the sawtooth waveform presentations. The sine-wave and rectangular wave conditions did not differ significantly from each other.

There were, moreover, a significant Waveform by Melody interaction $(F=4.39$, $\mathrm{df}=6 / 1181$, $\mathrm{p}<.0004)$, a significant Waveform by Distortion interaction $(F=2.30, \mathrm{df}=10 / 1181, \mathrm{p}<.01)$, and a significant Melody by Distortion interaction ( $F$ $=3.50, \mathrm{df}=14 / 1181, \mathrm{p}<.0001)$.

\section{CONCLUSION AND DISCUSSION}

Melodies which have been distorted in such a way that "tone height" is changed but in which "chroma" is maintained are not easy to identify. However, the present study demonstrated that identification under these circumstances can occur. Consequently, subjects were gaining information regarding the melody from the inappropriate octaves. In the case of the random octave distortion, the information is likely to be obtained from the similarity of the sounds of the octaves-the "chroma" of the tones. That is, octave generalization was enabling subjects to make correct identifications. Octave harmonics do enhance the identification, but they are not necessary for identification to occur. It is obvious also that there are differences among melodies which result in some melodies being more easily recognizable than others in the random octave distortion. In the alternating octave conditions, it is conceivable that subjects recognized the melodies on the basis of every other tone being like the undistorted sequence. It seems unlikely that the high level of recognition that was found in the present study can be explained by identification on the basis of every other tone in a seven-tone sequence. It is argued that octave generalization is the preeminent means by which recognition occurred in the alternating octave condition.

A process which may be operating to diminish subjects' ability to identify the distorted melodies of the present study is primary auditory stream segregation (PASS) (e.g., Bregman \& Campbell, 1971). When tones are presented in a relatively rapid sequence, a listener typically shows an inability to judge the order of the tones in the sequence. Consequently, in the present study, subjects may sometimes be unable to identify the distorted melodies because they are grouping the tones by similar tonal height rather than by order of presentation. If this is the case, further experiments would show an influence of manipulation of the duration of tones in a distorted melody on the identification of that melody because the temporal dimension seems to be of major importance in PASS.

The goal of the present study was to determine if identification could occur when octave information was all a subject had to deal with. Consequently, a discussion of the conditions which were apparently not recognized is entered into with caution. It cannot be concluded, for example, that subjects do not use the maintained fifth, fourth, and third information in a similar fashion to the way in which they seem to use octave information. The present data are not supportive of a notion of "harmonic generalization," but further work needs to be done to determine if there is an analog of octave generalization relative to the other important intervals of the harmonic series found in western music. 


\section{REFERENCES}

Bregman, A. S.. \& Campeell, J. Primary auditory stream segregation and perception of order in rapid sequences of tone. Journal of Experimental Psychology, 1971, 89, 244-249.

CoOper. P. Perspectives in music theory. New York: Dodd, Mead. 1973.

Deutsch, D. Music recognition. Psychological Review, 1969, 76, 300-307.

De UTSCH. D. Octave generalization and tune recognition. Perception \& Psychophysics, 1972, 11, 411-412.

Dowling. W. J. Recognition of melodic transformations: Inversions, retrograde, and retrograde inversions. Perception \& Psychophysics, 1972, 12, 417-421.
Dowling, W. J., \& Fubitani, D. Contour, interval, and pitch recognition in memory for melodies. Journal of the Acoustical Society of America, 1971, 49, 524-531.

RÉvÉsz, G. Zur Grundlegung der Tonpsychologie. Leipzig: Veit, 1913.

von FIEANDT, K. The world of perception. Homewood, Ill: Dorsey Press, 1966.

White, B. W. Recognition of distorted melodies. A merican Journal of Psychology, 1960, 73, 100-107.

Young, R. W. A standard system of musical notation. Journal of the Acoustical Society of America, 1939, 11, 134.

(Received for publication August 19, 1976; revision accepted March 30, 1977.) 